\title{
Hydrogen Evolution Ability of Selected Pure Metals and Galvanic Corrosion Behavior between the Metals and Magnesium
}

\author{
Zhen Luo, Kaili Song, Guijuan Li, and Lei Yang* \\ Key Lab. for Anisotropy and Texture of Materials, Education Ministry of China, School of Materials Science and Engi- \\ neering, Northeastern University, Shenyang, 110819, PR China
}

\begin{abstract}
The cathodic hydrogen evolution ability of different pure metals and their long term galvanic corrosion behavior with pure $\mathrm{Mg}$ were investigated. The hydrogen evolution ability of pure $\mathrm{Ti}, \mathrm{Al}, \mathrm{Sn}$ and $\mathrm{Zr}$ is weak, while that of $\mathrm{Fe}, \mathrm{W}, \mathrm{Cr}$, and $\mathrm{Co}$ is very strong. Initial polarization test could not completely reveal the cathodic behavior of the tested metals during long term corrosion. The cathodic hydrogen evolution ability may vary significantly in the long term galvanic tests for different metals, especially for $\mathrm{Al}$ whose cathodic current density reduced to $1 / 50$ of the initial value. The anodic polarization shows that $\mathrm{Al}$ and $\mathrm{Sn}$ as alloying elements are supposed to provide relatively good passive effect for $\mathrm{Mg}$ alloy, while $\mathrm{Ag}$ can provide a slight passive effect and $\mathrm{Zn}$ has little passive effect.
\end{abstract}

Keywords : Magnesium, Hydrogen Evolution, Galvanic Corrosion, Pure Metals

Received : 4 May 2020, Accepted : 4 August 2020

\section{Introduction}

Magnesium alloy is very prospective for applications in many fields such as aerospace, electronics, medical, automobile and military manufacturing due to its excellent specific strength, thermal conductivity, processing performance and relatively low cost [1-10]. However, one of the main reasons limiting the application of magnesium alloy is its poor corrosion resistance in the aqueous environment. The oxide film produced by the oxidation of magnesium is porous, which cannot effectively prevent the corrosion of magnesium matrix $[11,12]$. Besides, because of the low corrosion potential of pure magnesium (the standard electrode potential is only $-2.73 \mathrm{~V}$ ), other metallic elements in the alloy, which have higher corrosion potential than magnesium, are easy to form galvanic corrosion with magnesium to accelerate corrosion process of the alloy [13-15]. The ability to form galvanic corrosion

*E-mail address: yangl@atm.neu.edu.cn

DOI: https://doi.org/10.33961/jecst.2020.00983

This is an open-access article distributed under the terms of the Creative Commons Attribution Non-Commercial License (http://creativecommons.org/licenses/by-nc/4.0)
which permits unrestricted non-commercial use, distribution, and reproduction in any which permits unrestricted non-commercial use, distri
medium, provided the original work is properly cited. between different metals and magnesium is different but there are few reports about the galvanic corrosion between different alloying elements and magnesium $[16,17]$. The cathodic reaction for Mg alloys in aqueous solution is mainly hydrogen evolution reaction. Thus, measuring the hydrogen evolution ability can indirectly evaluate the extent of galvanic corrosion between magnesium and other metals. Therefore, this work studied the cathodic hydrogen evolution ability of different pure metals which either can be added in $\mathrm{Mg}$ as alloying elements or introduced as impurities. Further, the long term galvanic corrosion behavior between $\mathrm{Mg}$ and other metals was also investigated to clarify the change of the hydrogen evolution ability of different metals with corrosion progressing due to film formation.

\section{Experimental Procedures}

The cathodic electrodes used for this investigation were pure metals ( $\mathrm{Ti}, \mathrm{Zn}, \mathrm{Cu}, \mathrm{Fe}, \mathrm{W}, \mathrm{Cr}, \mathrm{Co}, \mathrm{Al}, \mathrm{Ag}$, $\mathrm{Sn}$ and $\mathrm{Zr}$ ). They are selected since these elements are the common alloying elements or impurities. The surface area of each used cathodic electrode is $0.5 \mathrm{~cm} \times 0.5 \mathrm{~cm}$. The purity of all studied metals is higher than $99.9 \mathrm{wt} \%$ and the purity of pure $\mathrm{Al}$ and 
$\mathrm{Sn}$ is higher than $99.99 \mathrm{wt} \%$. All electrochemical experiments were carried out in $0.6 \mathrm{M} \mathrm{NaCl}$ solution. The electrodes were uniformly polished using 400\#, $800 \#, 1200 \#, 1500 \#$ and finally $2000 \#$ grit $\mathrm{SiC}$ paper. The electrochemical test device used in experiments is Versa STAT V3 electrochemical workstation produced by US Princeton Corporation. A three-electrode system is applied, with a saturated calomel electrode (SCE) as the reference electrode, a platinum plate as the counter electrode, and samples as the working electrode. The scan rate was $5 \mathrm{mV} / \mathrm{s}$ for cathodic polarization. Using this relatively fast scan rate is to minimize the variation of surface condition during cathodic polarization. The scan rate was $0.5 \mathrm{~m} \mathrm{~V} / \mathrm{s}$ for anodic polarization measurement. Using this relatively slow scan rate is to allow the formation of oxide film and obtain accurate breakdown potential of the film. A big piece of pure $\mathrm{Mg}$, with exposed surface area of $6.0 \mathrm{~cm} \times 12.0 \mathrm{~cm}$, was used as anode and pure metal electrodes were used as cathode in galvanic corrosion test. The

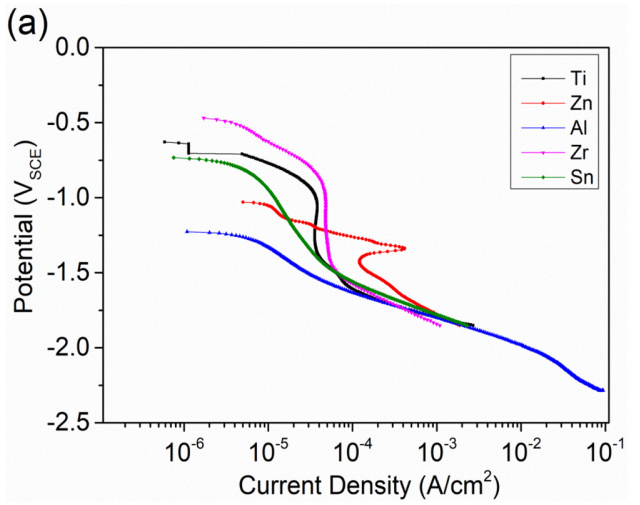

surface area of pure $\mathrm{Mg}$ (anode) is much bigger than that of other pure metals (cathodes). This is to ensure the mixed corrosion potential is close to $\mathrm{Mg}$, which is similar to the condition of $\mathrm{Mg}$ alloys. Before galvanic corrosion, the pure $\mathrm{Mg}$ was soaked into $0.6 \mathrm{M} \mathrm{NaCl}$ solution for about $30 \mathrm{~min}$ until the corrosion potential reached relatively stable, and then other pure metal was connected to start the galvanic corrosion test. The galvanic corrosion test was performed by the electrochemical workstation mentioned above.

\section{Results and Discussion}

\subsection{Cathodic polarization tests}

After obtaining the data of cathodic polarization tests on the pure metals, the ohmic potential drop (IR Drop) was removed, and the corresponding cathodic polarization curves were shown in Fig. 1. Since the corrosion potential of $\mathrm{Mg}$ alloys is about $-1.7 \mathrm{~V}_{\mathrm{SCE}}$, the cathodic current density for different metals at $1.7 \mathrm{~V}_{\mathrm{SCE}}$ was plotted and compared, as shown in Fig.

(b)

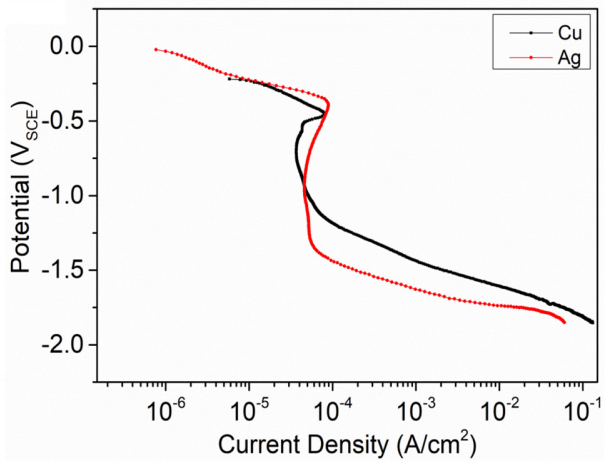

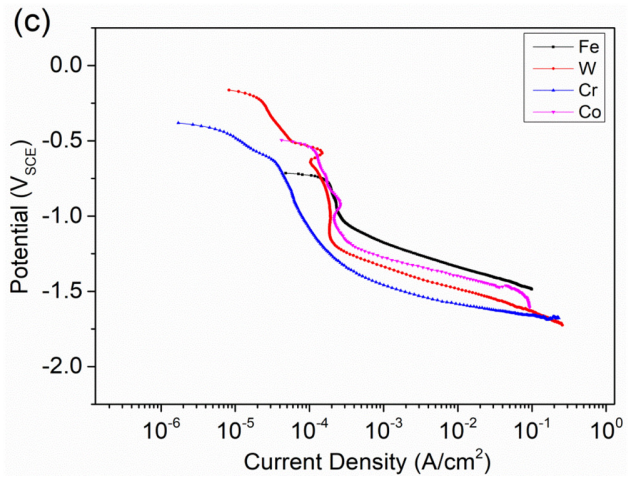

Fig. 1. Cathodic polarization curves of the studied pure metals in $3.5 \mathrm{wt} \% \mathrm{NaCl}$ solution, showing their hydrogen evolution ability as cathodes: (a) low current density group; (b) medium current density group; (c) high current density group. 
(a)

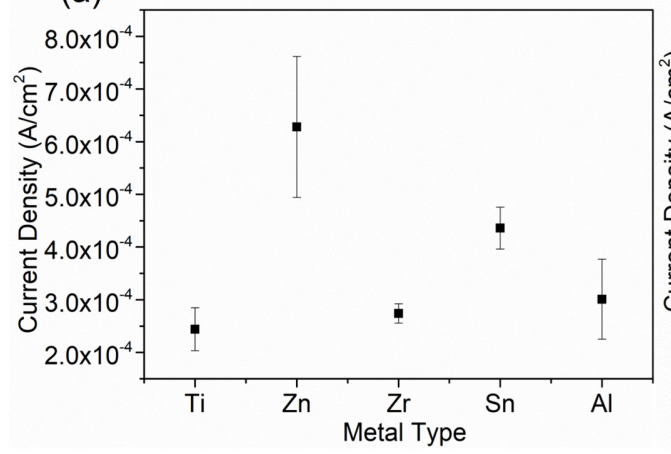

(b)

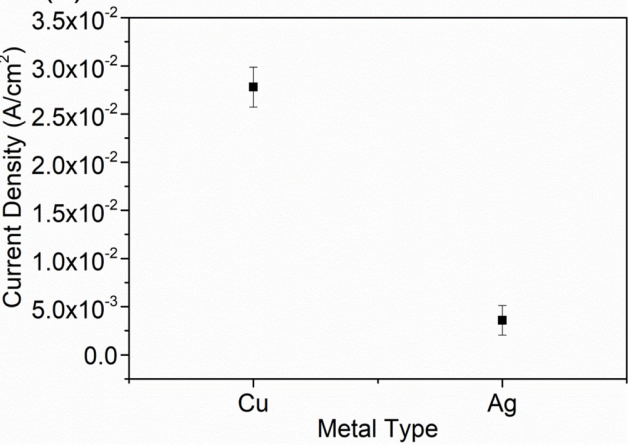

(c)

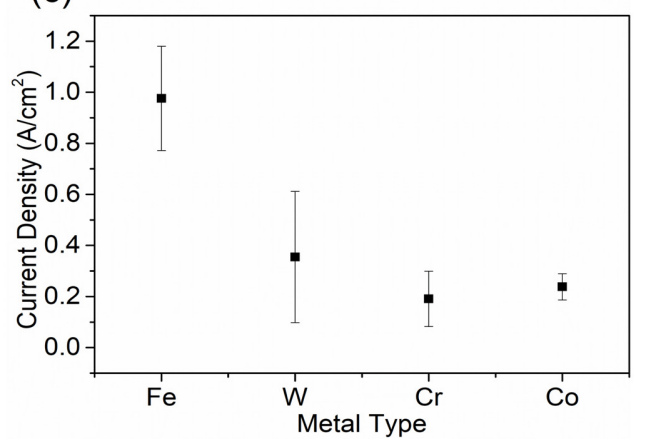

Fig. 2. Cathodic current density of the studied pure metals in $3.5 \mathrm{wt} \% \mathrm{NaCl}$ solution at $-1.7 \mathrm{~V}_{\mathrm{SCE}}$ : (a) low current density group; (b) medium current density group; (c) high current density group.

2. Generally, Fe, W, Cr, Co and $\mathrm{Cu}$ were regarded as impurities that can significantly accelerate the corrosion of $\mathrm{Mg}$ alloys. $\mathrm{Fe}, \mathrm{W}, \mathrm{Cr}, \mathrm{Co}$ and $\mathrm{Cu}$ can support very large cathodic hydrogen reduction current density, as revealed in Fig. 2. For $\mathrm{Fe}, \mathrm{W}, \mathrm{Cr}$, $\mathrm{Co}$ and $\mathrm{Cu}$, the hydrogen reduction ability of $\mathrm{Cu}$ is the weakest, which is about $1 / 10$ of other 3 elements. Ag is an interesting element. Although the corrosion potential of Ag was the highest in the studied metals, Ag only showed the medium ability of supporting hydrogen reduction. The cathodic current density of $\mathrm{Ag}$ at 1.7 $\mathrm{V}_{\mathrm{SCE}}$ was about $3.4 \mathrm{~mA} / \mathrm{cm}^{2}$. Ti and $\mathrm{Zr}$ showed very weak cathodic hydrogen reduction ability, with only about $0.25 \mathrm{~mA} / \mathrm{cm}^{2}$ cathodic current density at 1.7 $\mathrm{V}_{\mathrm{SCE}}$. Ti has very low solid solubility in $\mathrm{Mg}$ and it does not form second phase particles with $\mathrm{Mg}$. Ti can be used as a grain refiner for some $\mathrm{Mg}$ alloys. The weak hydrogen reduction ability of $\mathrm{Ti}$ and its low solid solubility in $\mathrm{Mg}$ indicate the galvanic corrosion effect of Ti in $\mathrm{Mg}$ almost need not be considered. $\mathrm{Zr}$ is the most common grain refiner for $\mathrm{Al}$-free $\mathrm{Mg}$ alloy, whose content is generally below $0.6 \mathrm{wt} \%$ [18].
This indicates a small amount of $\mathrm{Zr}$, as long as it does not combine with other elements to form the second phase, should not be a problem in terms of galvanic corrosion with $\mathrm{Mg}$. $\mathrm{Zn}, \mathrm{Sn}$ and $\mathrm{Al}$ are common alloying elements for $\mathrm{Mg}$ alloy. They are generally added as the main alloying elements to obtain good mechanical properties $[19,20]$. Their content in $\mathrm{Mg}$ is generally between $1 \mathrm{wt} \%$ to $10 \mathrm{wt} \%$. The hydrogen reduction ability of $\mathrm{Zn}, \mathrm{Sn}$ and $\mathrm{Al}$ is relatively low. The cathodic current density for $\mathrm{Zn}, \mathrm{Sn}$ and $\mathrm{Al}$ at -1.7 $\mathrm{V}_{\text {SCE }}$ were about $0.65 \mathrm{~mA} / \mathrm{cm}^{2}, 0.45 \mathrm{~mA} / \mathrm{cm}^{2}$ and 0.3 $\mathrm{mA} / \mathrm{cm}^{2}$, respectively. In summarize, $\mathrm{Ti}, \mathrm{Al}, \mathrm{Sn}$, and $\mathrm{Zr}$ have lower cathodic current density, while $\mathrm{Fe}, \mathrm{Cr}$, Co and $\mathrm{W}$ behave inversely. As a consequence, it is recognized that $\mathrm{Ti}, \mathrm{Al}, \mathrm{Sn}$, and $\mathrm{Zr}$ have weak hydrogen evolution ability and can be alloyed with magnesium in terms of corrosion property. Oppositely, Fe, $\mathrm{Cr}, \mathrm{Co}$ and $\mathrm{W}$ are strong in hydrogen evolution and can accelerate the galvanic corrosion of magnesium alloys significantly, which should be avoided even as impurities. 
(a)

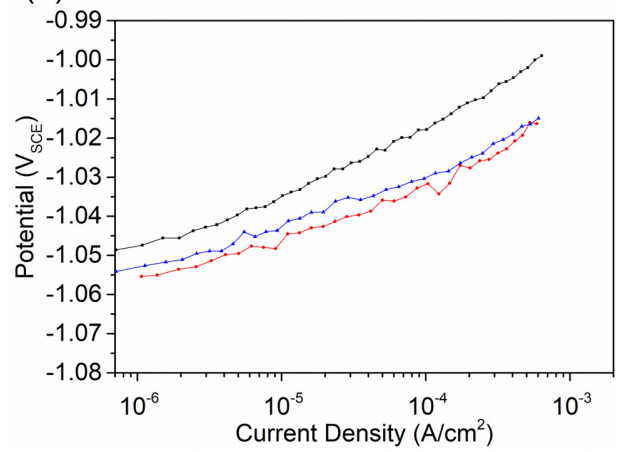

(c)

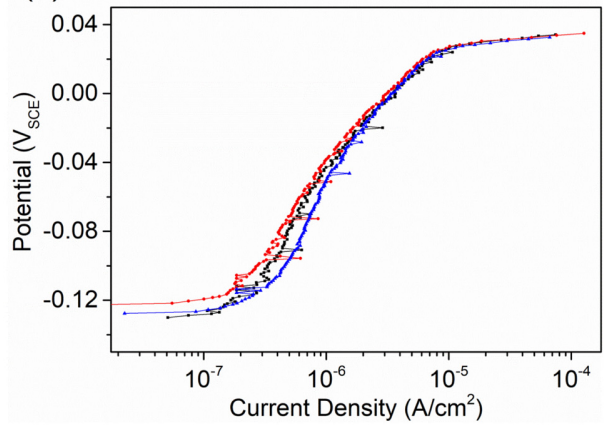

(b)

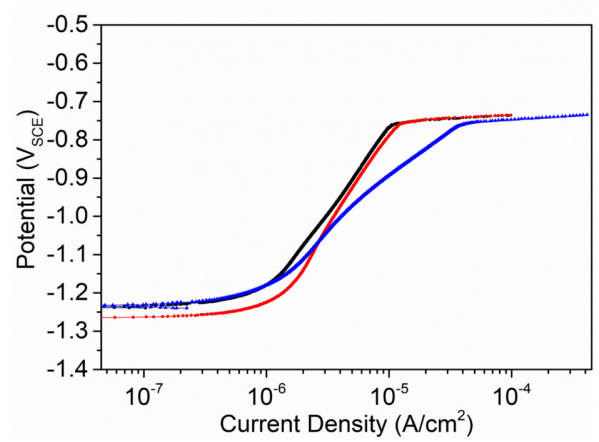

(d)

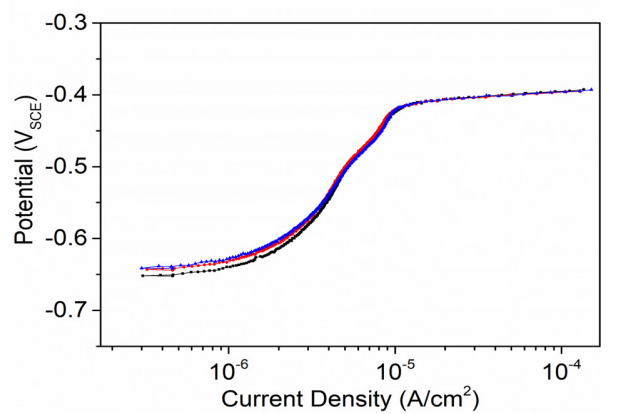

Fig. 3. Anodic polarization curves of studied metals in $3.5 \mathrm{wt} \% \mathrm{NaCl}$ solution at $0.5 \mathrm{mV} / \mathrm{s}$ scan rate: (a) $\mathrm{Zn}$, (b) $\mathrm{Al}$, (c) $\mathrm{Ag}$ and (d) Sn. There are three replicas for each metal.

\subsection{Anodic polarization tests}

Anodic polarization was performed on pure $\mathrm{Zn}, \mathrm{Al}$, $\mathrm{Ag}$, and Sn (Fig. 3) as they have relatively large solid solubility and are often used as main alloying elements in Mg alloy. Performing this test is to indirectly check if they can provide protective effect on the corrosion of $\mathrm{Mg}$ alloy when they are oxidized to corrosion products. $\mathrm{Zn}$ does not show passive behavior, as the current density increases stably with increasing potential. But $\mathrm{Ag}, \mathrm{Sn}$, and Al show passive effect and the breakdown potential can be seen on the anodic polarization curves. The potential ranges of passive region for $\mathrm{Al}, \mathrm{Sn}$, and $\mathrm{Ag}$ are $430 \mathrm{mV}, 250 \mathrm{mV}$, and $110 \mathrm{mV}$, respectively. This indicates the protective effect of the oxides of alloying elements might be in the following order $\mathrm{Al}>\mathrm{Sn}$ $>$ Ag. The enhanced passive effect due to alloying with $\mathrm{Al}, \mathrm{Sn}$ and $\mathrm{Ag}$ were also observed in $\mathrm{Mg}$ alloys [21-24]. This is consistent with our study. Some work also reported that $\mathrm{Zn}$ alloying can improve the stability of corrosion film of $\mathrm{Mg}$ alloy slightly
$[25,26]$, which is not fully in agreement with our study on pure $\mathrm{Zn}$. However, by considering the relatively strong cathodic role of $\mathrm{Zn}$ and $\mathrm{Zn}$-containing phases and the weak or no passive effect of $\mathrm{Zn}$-containing film, it is reasonable to infer that alloying with $\mathrm{Zn}$ could not improve corrosion resistance of $\mathrm{Mg}$.

\subsection{Galvanic corrosion tests}

The curves of potential and current density variation as a function of time during galvanic coupling between $\mathrm{Mg}$ and other metals are presented in Fig. 4. The mixed potential of all the galvanic couples only varies slightly, around $-1.68 \mathrm{~V}_{\mathrm{SCE}}$. Thus, the potential is considered to be similar and its effect on current is ignored. The initial current density for all the galvanic couples was similar to the value obtained by the potentiodynamic polarization test. However, with increasing time, the current density varied differently for different metals, which indicates the initial cathodic polarization behavior could not completely 
(a)

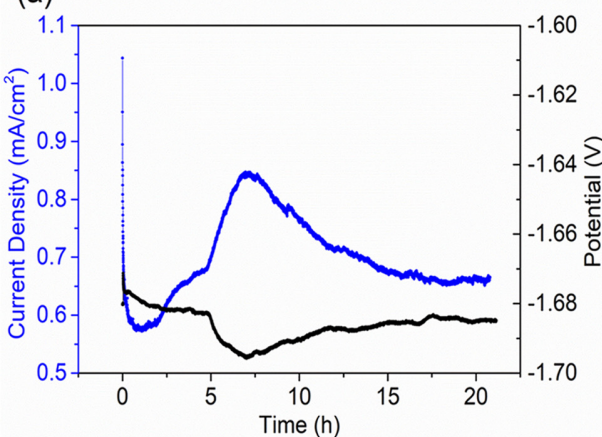

(c)

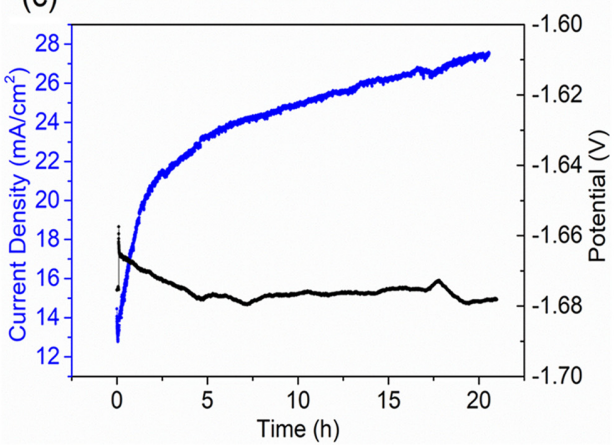

(e)

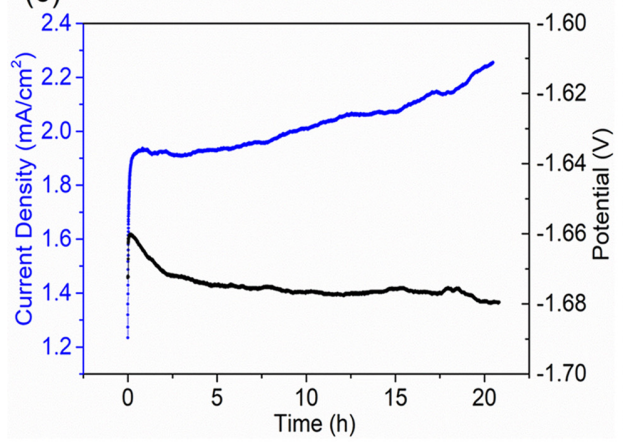

(b)

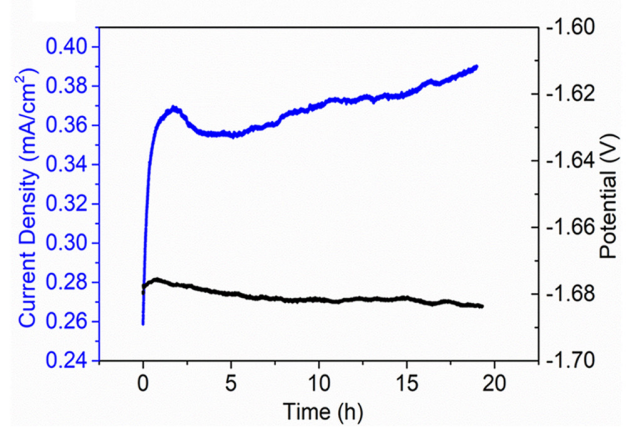

(d)

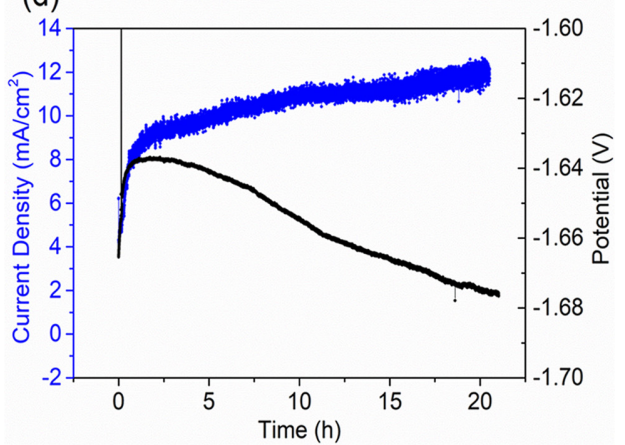

(f)

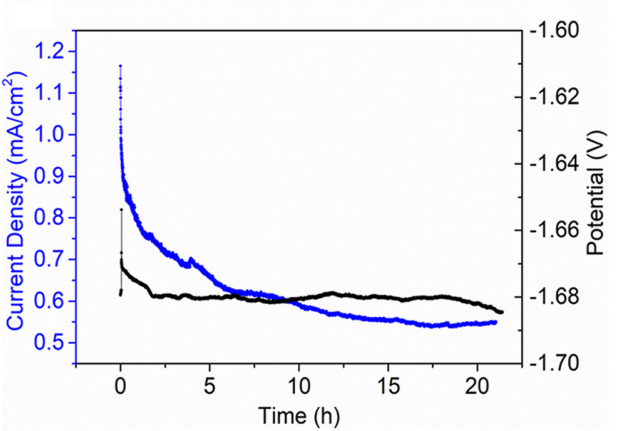

(g)

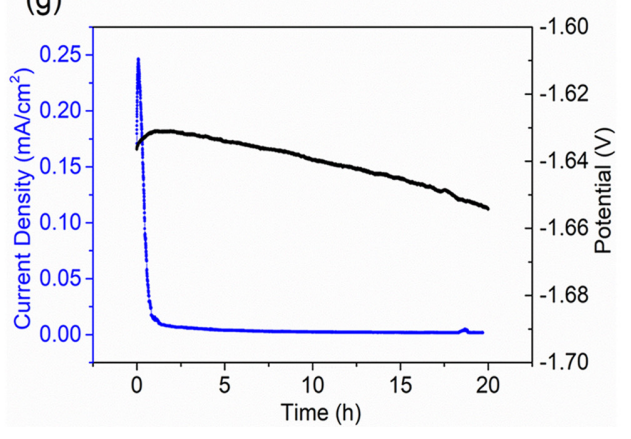

Fig. 4. Variation of galvanic current density and mixed potential of $\mathrm{Mg}$ and other metals during galvanic corrosion test in $3.5 \mathrm{wt} \% \mathrm{NaCl}$ solution for at least $20 \mathrm{~h}$ : (a) Mg-Sn; (b) Mg-Zr; (c) Mg-Cu; (d) Mg-Ag; (e) Mg-Ti; (f) Mg-Zn; (g) Mg-Al. 
reveal the long term galvanic corrosion behavior between $\mathrm{Mg}$ and other metals. The variation of current density on pure Sn was relatively small, which decreased initially and then increased, and finally kept relatively stable at about $0.7 \mathrm{~mA} / \mathrm{cm}^{2}$. It was also been studied by Cain et al. [20] that $\mathrm{Mg}-\mathrm{Sn}$ alloys have lower corrosion rates when compared to high purity $\mathrm{Mg}$, especially for $\mathrm{Sn}$ addition of $10 \%$. This indicates Sn does not generate strong cathodic hydrogen evolution effect, which agrees with our work. For $\mathrm{Zr}, \mathrm{Cu}$, and $\mathrm{Ag}$, the current density increased initially and then reached a relatively stable value after about 2.5 hours. The increased percentages for $\mathrm{Zr}, \mathrm{Cu}$, and $\mathrm{Ag}$ are about $50 \%, 100 \%$, and $200 \%$, respectively. For Ti, the current density increased very fast in the first 20 minutes and then increased slowly but linearly, which increased by $300 \%$ and was still increasing after 20 hours. Therefore, the enhanced cathodic activity should be considered when alloying with Ag and Ti during long term corrosion. The accelerating corrosion behavior is also reported in Ag-containing alloys [23,27].

For $\mathrm{Zn}$ and $\mathrm{Al}$, the current density decreased with increased time and then kept stable. However, the decreased degree has a large difference. The stable current density for $\mathrm{Zn}$ was about half of the current density initially. Yim [28] studied the as-extruded TZ alloys and found that both the corrosion potential measured by potentiodynamic test and the current density at cathodic region increased with increase of $\mathrm{Zn}$ content. It means $\mathrm{Zn}$ content should be controlled strictly in magnesium alloys though the current density of $\mathrm{Mg}-\mathrm{Zn}$ galvanic couple is low. But the stable current density for Al was only about $1 / 50$ of the initial value. This indicates $\mathrm{Al}$ is not only a weak cathode but also has the potential to significantly reduce its cathodic role when alloying in $\mathrm{Mg}$, which is quite interesting. However, the reported corrosion behavior of $\mathrm{Mg}-\mathrm{Al}$ alloys is very complexed. Bland [29] et al. studied the Mg-Al alloys with $\geq 3 \mathrm{wt} \% \mathrm{Al}$ content and found that deeper local corrosion occurs. The current density of the alloys is high in cathodic polarization test. This is not consistent with our study. According to our result of $\mathrm{Mg}-\mathrm{Al}$ galvanic corrosion test, such low current density equals to pretty good corrosion resistance. Therefore, we deduce that impurity elements, such as Fe, may be the cause for the high corrosion rate of the reported $\mathrm{Mg}-\mathrm{Al}$ alloys [27]. Effects of Fe in magnesium alloys have been studied and it is confirmed that Fe can significantly increase corrosion rate by forming Ferich particles in magnesium alloys [30-32]. Generally, less than $9 \mathrm{wt} \% \mathrm{Al}$ is alloyed in $\mathrm{Mg}$ in commercial Mg alloys [27,33]. Based on our study, higher amount of $\mathrm{Al}$ is suggested to be alloyed for new alloys development in terms of long term corrosion resistance.

\section{Conclusions}

The hydrogen evolution ability of selected pure metals and their long term galvanic corrosion behavior with pure $\mathrm{Mg}$ were studied by polarization and galvanic coupling tests in the present work. The hydrogen evolution ability of pure $\mathrm{Ti}, \mathrm{Al}, \mathrm{Sn}$, and $\mathrm{Zr}$ is low at the general corrosion potential of $\mathrm{Mg}(-1.7$ $\mathrm{V}_{\mathrm{SCE}}$ ). Thus, they can be alloyed for the development of corrosion resistant $\mathrm{Mg}$ alloys. $\mathrm{Fe}, \mathrm{Co}, \mathrm{Cr}$, and $\mathrm{W}$ should be avoided for obtaining acceptable corrosion resistance. $\mathrm{Cu}, \mathrm{Ag}$ and $\mathrm{Zn}$ could be used as alloying elements if high corrosion resistance is not priority. Long term galvanic tests indicate cathodic inhibition is significant for pure $\mathrm{Al}$, while slight cathodic activation occurs for $\mathrm{Zr}$, $\mathrm{Ti}, \mathrm{Ag}$ and $\mathrm{Cu}$.

\section{Acknowledgement}

This work is supported by the National Training Program of Innovation and Entrepreneurship for Undergraduates (Grant No.201910145113); the Fundamental Research Funds for the Central Universities (Grant No.N182410001). The first author thanks to the support of Chao Yang on experiments process and test equipment.

\section{References}

[1] T.B. Abbott, Corros., 2015, 71(2), 120-127.

[2] V. Bazhenov, A. Koltygin, A. Komissarov, A. Li, V. Bautin, R. Khasenova, A. Anishchenko, A. Seferyan, J. Komissarova and Y. Estrin, J. Magnesium Alloys, 2020, $8,352-363$.

[3] F. Guo, L. Jiang, Y. Ma, L. Liu, Z. Zhang, M. Yang, D. Zhang and F. Pan, Scr. Mater., 2020, 179, 16-19.

[4] J.J. Han, P. Wan, Y. Ge, X.M. Fan, L.L. Tan, J.J. Li and K. Yang, Mater. Sci. Eng., C, 2016, 58, 799-811.

[5] K. Hong, H. Park, Y. Kim, M. Knapek, P. Minarik, K. Mathis, A. Yamamoto and H. Choe, J. Mech. Behav. Biomed. Mater., 2019, 98, 213-224.

[6] S.S. Jamali, S. E. Moulton, D. E. Tallman, M. Forsyth, 
J. Weber and G.G. Wallace, Electrochim. Acta, 2015, 152, 294-301.

[7] S. Nezamdoust, D. Seifzadeh and Z. Rajabalizadeh, $J$. Magnesium Alloys, 2019, 7(3), 419-432.

[8] Y. Uematsu, K. Tokaji and M. Matsumoto, Mater. Sci. Eng., $A, 2009,517(1-2), 138-145$.

[9] X.D. Yan, P. Wan, L.L. Tan, M.C. Zhao, L. Qin and K. Yang, Mater. Sci. Eng., C, 2018, 93, 565-581.

[10] C.H. Ye, T.F. Xi, Y.F. Zheng, S.Q. Wang and Y.D. Li, Trans. Nonferrous Met. Soc. China, 2013, 23(4), 9961001.

[11] S.H. Tamboli, V. Puri and R.K. Puri, Appl. Surf. Sci., 2010, 256(14), 4582-4585.

[12] S.F. Zhang, G.H. Hu, R.F. Zhang, Z.X. Jia, L.J. Wang, Y.J. Wang, C.Y. Hu and X.M. He, Trans. Nonferrous Met. Soc. China, 2010, 20, s660-s664.

[13] L.J. Liu and M. Schlesinger, Corros. Sci., 2009, 51(8), 1733-1737.

[14] I.B. Singh, M. Singh and S. Das, J. Magnesium Alloys, 2015, 3(2), 142-148.

[15] K. Xiao, C.F. Dong, D. Wei, J.S. Wu and X.G. Li, J. Wuhan University, Technology-Mater. Sci. Ed., 2016, 31(1), 204-210.

[16] M. Esmaily, J.R. Svensson, S. Fajardo, N. Birbilis, G.S. Frankel, S. Virtanen, R. Arrabal, S. Thomas and L. Johansson, Prog. Mater Sci., 2017, 89, 92-193.

[17] G.L. Song and A. Atrens, Adv. Eng. Mater, 2003, 5(12), 837-858.

[18] M. Colombo, E. Gariboldi and A. Morri, Mater. Sci. Eng., $A, \mathbf{2 0 1 8}, 713,151-160$.

[19] J.B. Go, J.H. Lee, H. Yu and S.H. Park, J. Alloys Compd., 2020, 82, 1534451.
[20] X.Y. Wang, Y.F. Wang, C. Wang, S. Xu, J. Rong, Z.Z. Yang, J.G. Wang and H.Y. Wang, J. Mater. Sci. Technol., 2020, 49, 117-125.

[21] T.W. Cain, C.F. Glover and J.R. Scully, Electrochim. Acta, 2019, 297, 564-575.

[22] S.J. Kim, S.J. Lee, J.Y. Jeong and K.H. Kim, Trans. Nonferrous Met. Soc. China, 2012, 22, s881-s886.

[23] D. Tie, F. Feyerabend, N. Hort, D. Hoeche, K.U. Kainer, R. Willumeit and W.D. Mueller, Mater. Corros., 2014, 65(6), 569-576.

[24] X.B. Zhang, Z.X. Ba, Z.Z. Wang, X.C. He, C. Shen and Q. Wang, Mater. Lett., 2013, 100, 188-191.

[25] N.C. Hosking, M.A. Strom, P.H. Shipway and C.D. Rudd, Corros. Sci., 2007, 49(9), 3669-3695.

[26] H.M. Jia, X.H. Feng and Y.S. Yang, Corros. Sci., 2017, 120, 75-81.

[27] I.Y. Mukhina, Met. Sci. Heat Treat., 2014, 56(5-6), 387393.

[28] C.D. Yim, S.K. Woo, J. Yang and B.S. You, Magnesium Technol., 2014, 331-334.

[29] L.G. Bland, L.C. Scully and J.R. Scully, Corros., 2017, 73(5), 526-543.

[30] L. Yang, G.K. Liu, L.G. Ma, E.L. Zhang, X.R. Zhou and G. Thompson, Corros. Sci., 2018, 139, 421-429.

[31] L. Yang, X.R. Zhou, M. Curioni, S. Pawar, H. Liu, Z.Y. Fan, G. Scamans and G. Thompson, J. Electrochem. Soc., 2015, 162(7), C362.

[32] L. Yang, X.R. Zhou, S.M. Liang, R. Schmid-Fetzer, Z.Y. Fan, G. Scamans, J. Robson and G. Thompson, J. Alloys Compd., 2015, 619, 396-400.

[33] Y.Q. He, C.Q. Peng, Y. Feng, R.C. Wang and J.F. Zhong, J. Alloys Compd., 2020, 834, 154344-154356. 